\title{
Design \& Analysis of Microstrip Patch Antenna Using Different Dielectric Materials for WiMAX Communication System
}

\author{
http://dx.doi.org/10.3991/ijes.v4i1.5569 \\ Md. Moidul Islam, Raja Rashidul Hasan, Md. Mostafizur Rahman, Kazi Saiful Islam, S.M. Al-Amin \\ American International University-Bangladesh (AIUB), Dhaka, Bangladesh
}

\begin{abstract}
This Paper presents Microstrip patch antenna for WiMAX communication system which operate at $5.8 \mathrm{GHz}$ frequency band. The main objective of this paper is to design and observe the performance of the designed microstrip patch antenna for different dielectric materials. The size of the designed antenna has been also miniaturized. Better performance is observed for FR4 and dupont-951 dielectric material. For FR4 radiation efficiency is-2.776 dB and total efficiency is $\mathbf{- 3 . 0 2 6} \mathrm{dB}$ at $5.8 \mathrm{GHz}$, this indicates better performance. And for dupont-951 the return loss is much lower comparing to the other dielectric materials used in this research, which is $\mathbf{- 1 6 . 6 0 9} \mathbf{~ d B}$. Also for dupont-951 and FR4, VSWR is found 1.35 and 1.7 respectively which is desirable. Also the size of the antenna has been reduced. In this paper we also observed and analyzed the radiation pattern of far field region, gain, radiation efficiency and total efficiency for different dielectric materials.
\end{abstract}

Index Terms-Microstrip patch antenna; WiMAX communication; dielectric materials; far field; return losses; Directivity

\section{INTRODUCTION}

Day by day our life become easier and comfortable with bless of Technology. Invention increases with the pursue of innovative people. WiMAX is one of the great inventions by those scientists. WiMAX is an acronym meaning "Worldwide Interoperability for Microwave Access" and it is a new in terms of a standard initiative. WiMAX is designed to extend local Wi-Fi network across greater distance. In this paper, our aim is to analyze the performance of an antenna by using dielectric material for using in WiMAX communication application system.

Microstrip antenna was proposed in early 1970 [1][2] and provides a great revolution in the field of antenna design and Research. Nowadays, microstrip patch antenna has become very popular and is widely used in many areas like in mobile communication, Wi-Fi and WiMAX applications. It is a popular printed resonant antenna for narrow-band microwave wireless links that require semihemispherical coverage. Due to its planar configuration and ease of integration with microstrip technology, the microstrip patch antenna has been heavily studied and is often used as elements for an array [3]. For designing and manufacturing, Microstrip antenna has low cost because of the simple two dimensional Physical geometry.

To minimize the cost, weight, power consumption and profile of antennas which are capable of maintaining high performance over a wide spectrum of frequencies is the goal to develop the communication System. We focused on improving the performance of WiMAX communication by designing of a microstrip patch antenna. To increase the performance of a microstrip patch antenna there are several methods like increasing the thickness of substrate, using low dielectric substrate, using of various impedance matching and feeding techniques [6].

This research paper is organized as follows: Section II explains the structure and design specifications of a microstrip patch antenna. Section III describes the simulations of designed device at cutoff frequency $5.8 \mathrm{GHz}$. Analysis of the simulated results for the designed microstrip patch antennas are described in this section. This paper ends with a conclusion in Section IV. CST Microwave Suite simulation results show better performance in terms of return loss, radiation efficiency and total efficiency.

\section{StRUCtURE AND Design SPECificAtions}

A microstrip patch antenna consists of a radiating patch on one side of a dielectric substrate which has a ground plane on the other side as shown in Fig 1. The patch is generally made of conducting material such as copper or gold and can take any possible shape. The radiating patch and the feed lines are usually photo etched on the dielectric substrate [4].

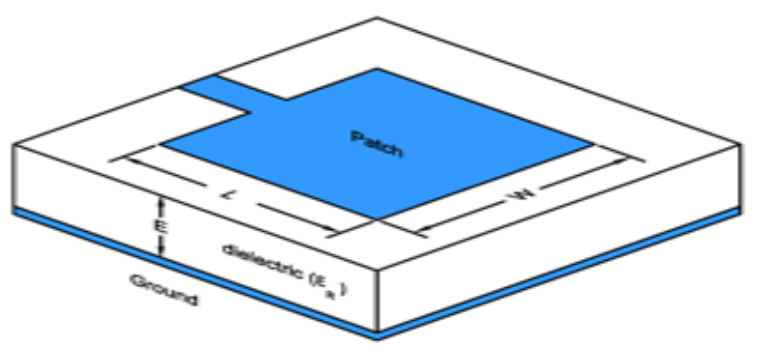

Figure 1. Structure of Patch antenna [3].

In these different layers different materials are used. Copper is used in ground plane, patch and microstrip line. In substrate layer different dielectric substrate materials are used. In this research different dielectric materials were used for specific cut-off frequency to analyze the performance of the antenna for WiMAX application. Table 1 shows the name of the layers and materials used in the microstrip patch antenna. In simulation software 
materials with loss effect were selected to get practical simulated results.

Table II shows the list of the dielectric materials used in this research purpose to analyze the performance of the antenna for $5.8 \mathrm{GHz}$.

TABLE I.

NAME OF THE LAYERS AND MATERIALS USED

\begin{tabular}{|l|l|}
\hline \multicolumn{1}{|c|}{ Layer Name } & \multicolumn{1}{c|}{ Material Name } \\
\hline Microstrip Line & Copper \\
\hline Patch & Copper \\
\hline Substrate & Dielectric substrate materials \\
\hline Ground plane & Copper \\
\hline
\end{tabular}

TABLE II.

LIST OF DIFFERENT DIELECTRIC MATERIALS USED IN THIS RESEARCH AND THEIR DIELECTRIC CONSTANTS

\begin{tabular}{|l|l|}
\hline Name of the dielectric materials & Dielectric constants $\left(\boldsymbol{\varepsilon}_{\mathbf{r}}\right)$ \\
\hline FR4 & 4.3 \\
\hline RTDuroid 5880 & 2.2 \\
\hline Arlon Di 522 & 2.5 \\
\hline Taconic RF 35P & 3.5 \\
\hline Bakelite & 4.8 \\
\hline Dupont-951 & 7.8 \\
\hline
\end{tabular}

The essential parameters require designing Microstrip Patch Antenna are:

Frequency of operation $\left(f_{o}\right)$ : The resonant or cut-off frequency of the antenna must be selected appropriately. WiMAX communication system uses $5.8 \mathrm{GHz}$ frequency. Thus the designed antenna must be able to operate at this frequency [6].

Dielectric constant of the substrate $(\varepsilon r)$ : 6 different dielectric materials were used in this research. Name of the dielectric materials and their dielectric constants are mentioned in table. A substrate with a high dielectric constant has been selected since it reduces the dimensions of the antenna [6].

Height of dielectric substrate $(h)$ : For the microstrip patch antenna used in WiMAX communication system should not be bulky. Hence, the height of the dielectric substrate used to design the antenna is $1.5 \mathrm{~mm}$ [6].

Calculation of effective dielectric constant, $\varepsilon_{\text {reff }}$ : Effective dielectric constant, $\varepsilon_{\text {reff }}$ can be calculated from the below equation.

$$
\varepsilon_{\mathrm{reff}}=\frac{\varepsilon_{\mathrm{r}+1}}{2}+\frac{\varepsilon_{\mathrm{r}-1}}{2}\left[1+12 \frac{h}{w}\right]^{1 / 2}
$$

Calculation of the width of the patch, W: The width of the patch can be calculated from the below equation.

$$
\mathrm{W}=\frac{C}{2 f} \frac{\sqrt{\frac{\left[\varepsilon_{r}+1\right]}{2}}}{}
$$

Calculation of the length of the patch, L: The effective length of the patch can be calculated from the below equation.

$$
L_{e f f}=\frac{C}{2 f \sqrt{\varepsilon_{\text {reff }}}}
$$

The length extension can be calculated from the below equation.

$$
\Delta \mathrm{L}=0.412 \mathrm{~h} \frac{\left(\varepsilon_{\mathrm{reff}}+0.3\right)\left(\frac{w}{h}+0.264\right)}{\left(\varepsilon_{\mathrm{reff}}-0.258\right)\left(\frac{w}{h}+0.8\right)}
$$

The actual length of the patch can be calculated from the below equation.

$$
\mathrm{L}=\mathrm{L}_{\mathrm{eff}}-2 \Delta \mathrm{L}
$$

Calculation of the length of the ground plane, $\mathrm{L}_{\mathrm{g}}$ :The length of the ground plane can be calculated from the below equation.

$$
L_{g}=6 h+L
$$

Calculation of the width of the ground plane, $\mathrm{W}_{\mathrm{g}}$ : The width of the ground plane can be calculated from the below equation.

$W_{g}=6 h+W$

Calculation of the length of the feed line, $L_{\mathrm{f}}$ :The length of the feed line can be calculated from the below equation.

$$
\begin{array}{r}
L_{f}=\frac{\lambda_{o}}{4 \sqrt{\varepsilon_{r}}} \\
\text { Where, } \lambda_{o}=\frac{C}{f_{o}}
\end{array}
$$

Calculation of the width of the feed line, $\mathrm{W}_{\mathrm{f}}$ : If $\mathrm{Z}_{\mathrm{c}}=50$ $\Omega$, the width of the feed line can be calculated from the below equation.

$$
\mathrm{Z}_{c}=\frac{120 \pi}{\sqrt{\varepsilon_{\text {reff } f}\left[\frac{W_{f}}{h}+1.393+0.667 \ln \left(\frac{W_{f}}{h}+1.444\right)\right.}}
$$

Calculation of the gap of the feed line, $G_{p f}$ :The gap of the feed line can be calculated from the below equation.

$$
G_{p f}=\frac{4.65 \times 10^{-9} x C}{f_{o \sqrt{2 \varepsilon_{\text {reff }}}}}
$$

\section{Analysis Of Simulated Results}

CST Microwave Suite was used to design microstrip patch antenna for $5.8 \mathrm{GHz}$ resonant frequency using different dielectric materials. Performances for different substrate materials were compared to observe for better performance. Return loss, radiation efficiency, total efficiency, VSWR are the most important factor for the performance analysis of a microstrip patch antenna.

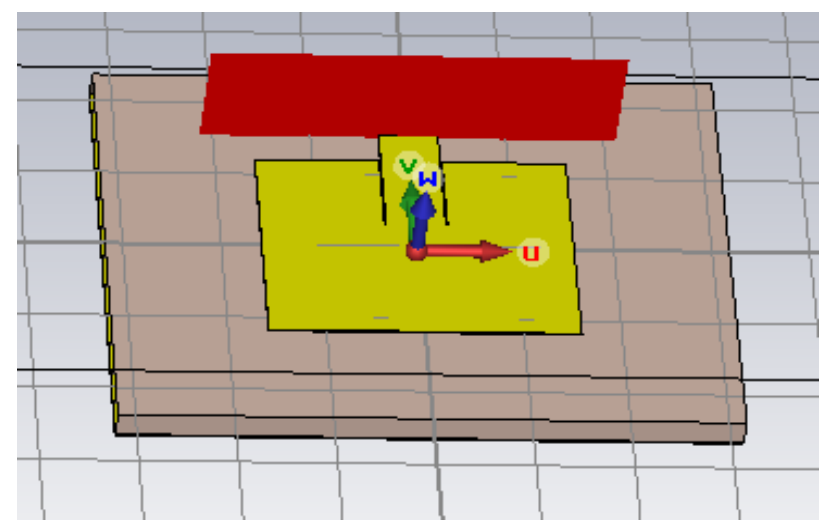

Figure 2. Designed Microstrip Patch Antenna for $5.8 \mathrm{GHz}$. 


\section{A. Performance of the antenna for FR4}

Fig. 3 shows the s-parameter graph for FR4. Sparameter represents how much power is reflected from antenna and is known as reflection coefficient or return loss. The less the value of $\mathrm{S}_{11}$ is, the better the performance. For better performance of microstrip patch antenna the value of return loss or $\mathrm{S}_{11}$ parameter should be less than $-10 \mathrm{~dB}$. In the figure the return loss is $-12.421397 \mathrm{~dB}$ at $5.8 \mathrm{GHz}$, which is better for antenna performance.

Fig. 4 shows the far field region. In the figure the total efficiency and radiation efficiency are mentioned. At 5.8 $\mathrm{GHz}$ the radiation efficiency is $-2.776 \mathrm{~dB}$ and total efficiency is $-3.026 \mathrm{~dB}$, which is better for the performance of antenna. From the figure it can be seen that the directivity is in $\mathrm{Z}$-axis on the XY plane. Directivity is $6.108 \mathrm{dBi}$. The top red color shows the radiation. Radiation increased from green to red in $\mathrm{Z}$ direction. Fig. 5 shows the far field

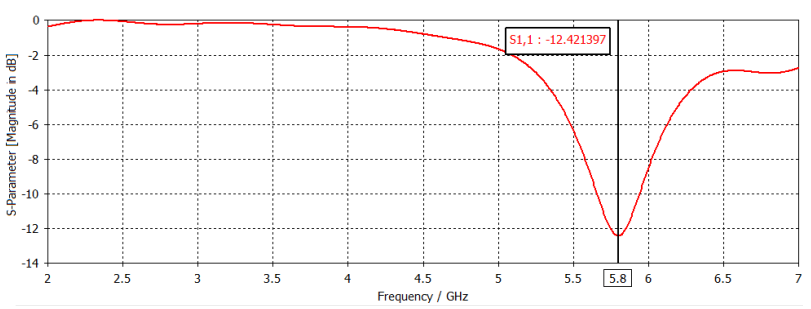

Figure 3. Return loss for FR4.

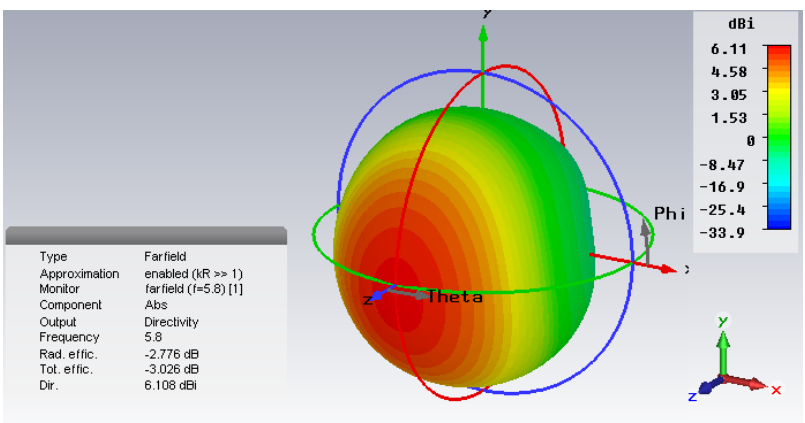

Figure 4. Far field region for FR4.

Farfield Gain Abs (Phi=90)

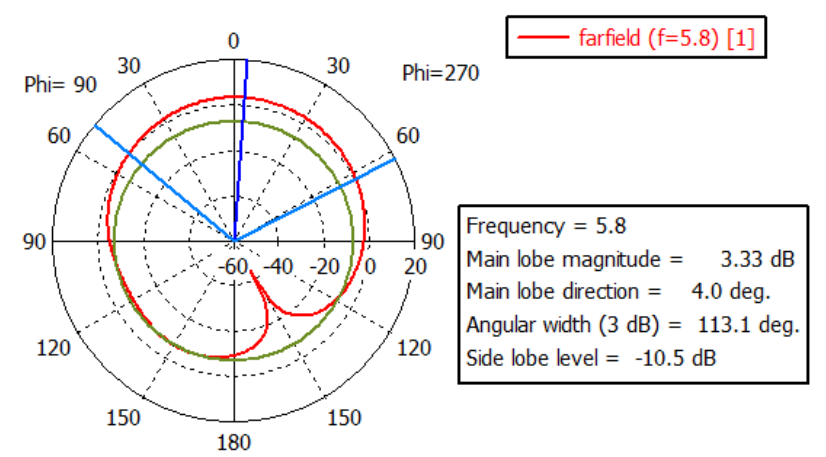

Theta / Degree vs. dB

Figure 5. Far field in polar view for FR4. in polar view for FR4. According to the figure at $5.8 \mathrm{GHz}$ angular width of half power beam is $113.1^{\circ}$ and side lobe level is $-10.5 \mathrm{~dB}$.

\section{B. Performance of the antenna for RTDuroid 5880}

Fig. 6 shows the return loss graph for RTDuroid 5880 . According to the figure the value of $S_{11}$ parameter is $9.6935619 \mathrm{~dB}$ at $5.8 \mathrm{GHz}$.

Fig.7 shows far field region for RTDuroid 5880. At 5.8 $\mathrm{GHz}$ the radiation efficiency is $-0.8192 \mathrm{~dB}$ and total efficiency is $-1.487 \mathrm{~dB}$, which is better for the performance of antenna. According to the fig. 7 the directivity is in Z-axis on the XY plane. Directivity is $7.282 \mathrm{dBi}$. Radiation increased from green to red in $\mathrm{Z}$ direction. Fig. 8 shows the far field in polar view for RTDuroid 5880. According to the figure at $5.8 \mathrm{GHz}$ angular width is $96.6^{\circ}$ and side lobe level is $-14.7 \mathrm{~dB}$.

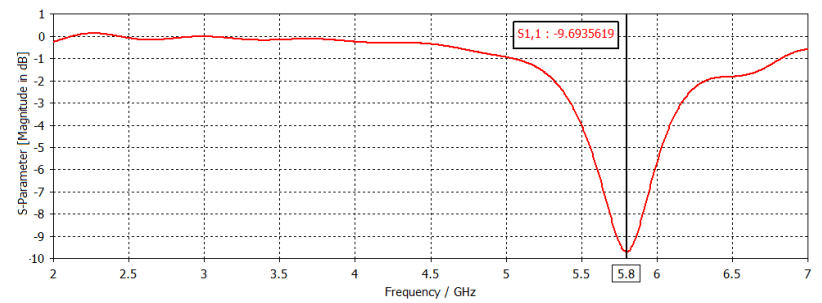

Figure 6. Return loss for RTDuroid 5880.

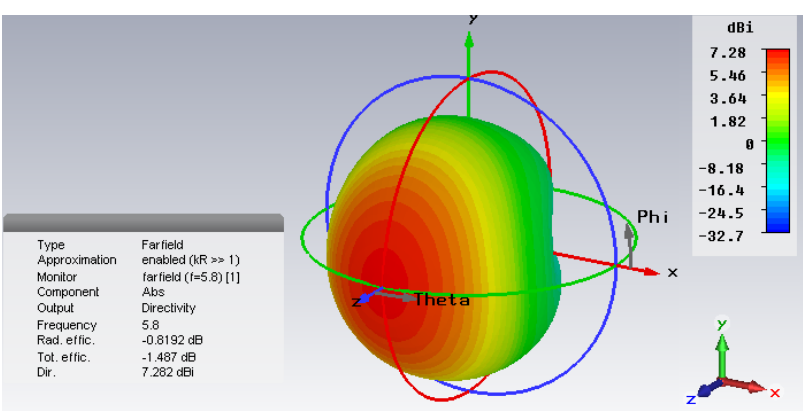

Figure 7. Far field region for RTDuroid 5880.

Farfield Gain Abs (Phi=90)

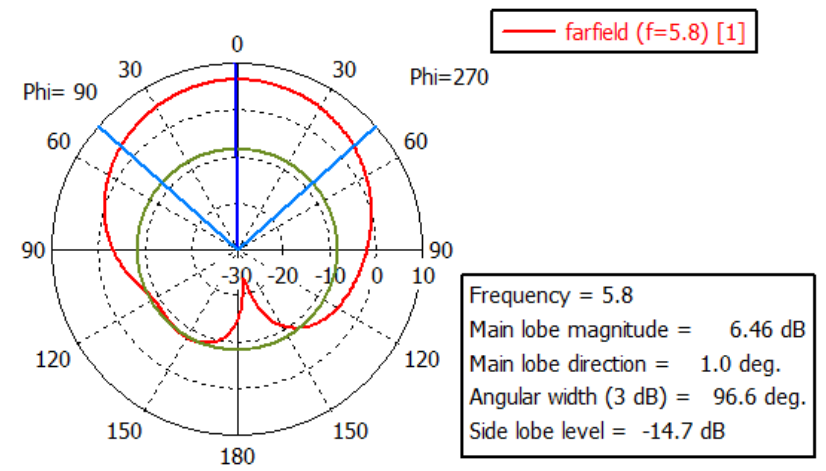

Theta / Degree vs. dB

Figure 8. Far field in polar view for RTDuroid 5880. 
PAPER

Design \& ANALysis of Microstrip PATCh ANTENNA USING DifFERENT DiElECTRIC MATERIALs FOR WiMAX...

\section{Performance of the antenna for Arlon Di 522}

Fig. 9 shows the return loss graph for Arlon Di 522. According to fig. 9, the value of return loss is $13.821792 \mathrm{~dB}$ at $5.8 \mathrm{GHz}$.

Fig. 10 shows the far field region for Arlon Di 522. At $5.8 \mathrm{GHz}$ the radiation efficiency is $-1.013 \mathrm{~dB}$ and total efficiency is $-1.553 \mathrm{~dB}$, which is better for the performance of antenna. According to fig. 10 directivity is in Zaxis on the XY plane. The value of directivity at $5.8 \mathrm{GHz}$ is $7.078 \mathrm{dBi}$. Fig. 11 shows the far field in polar view for Arlon Di 522. At $5.8 \mathrm{GHz}$ angular width is $94.9^{\circ}$ and side lobe level is $-15.3 \mathrm{~dB}$.

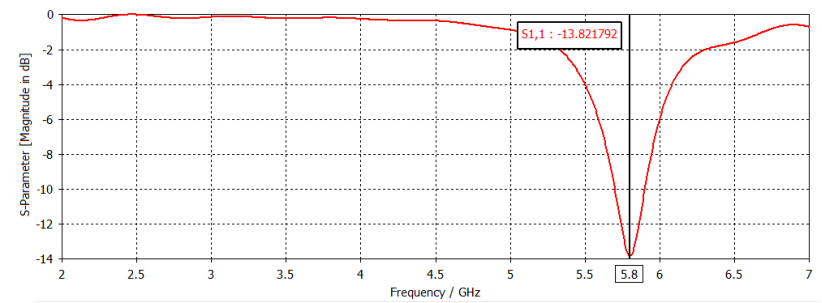

Figure 9. Return loss for Arlon Di 522.

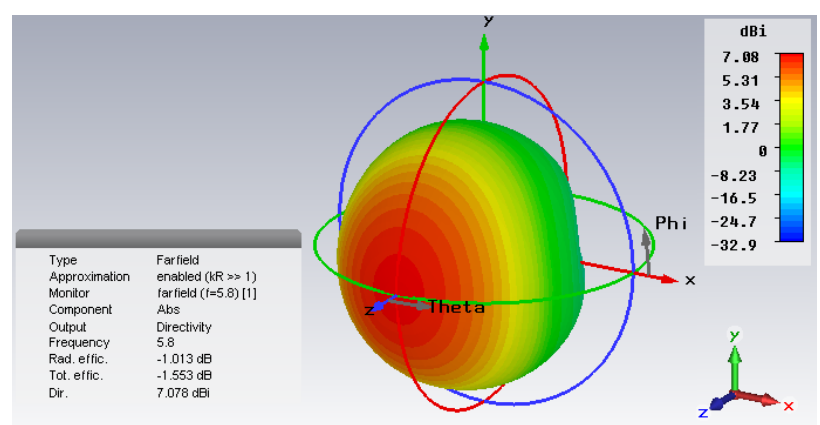

Figure 10. Far field region for Arlon Di 522.

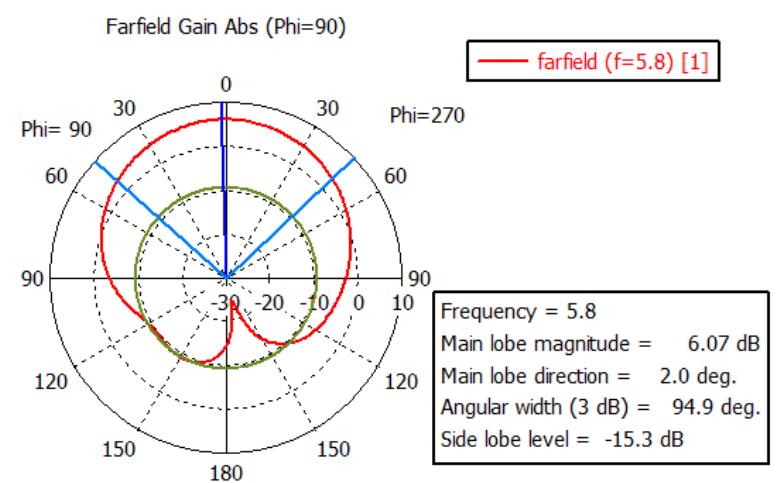

Theta / Degree vs. dB

Figure 11. Far field in polar view for Arlon Di 522.
D. Performance of the antenna for Taconic RF $35 P$

Fig. 12 shows the return loss graph for Taconic RF 35P. At $5.8 \mathrm{GHz}$ return loss is $-15.464453 \mathrm{~dB}$.

Fig. 13 shows the far field region. For $5.8 \mathrm{GHz}$ the radiation efficiency is $-1.380 \mathrm{~dB}$ and total efficiency is $1.640 \mathrm{~dB}$. Directivity is $6.609 \mathrm{dBi}$. Directivity is in Z-axis on the XY plane. Fig. 14 shows the far field in polar view. At $5.8 \mathrm{GHz}$ angular width is $105.3^{\circ}$ and side lobe level is $-12.4 \mathrm{~dB}$.

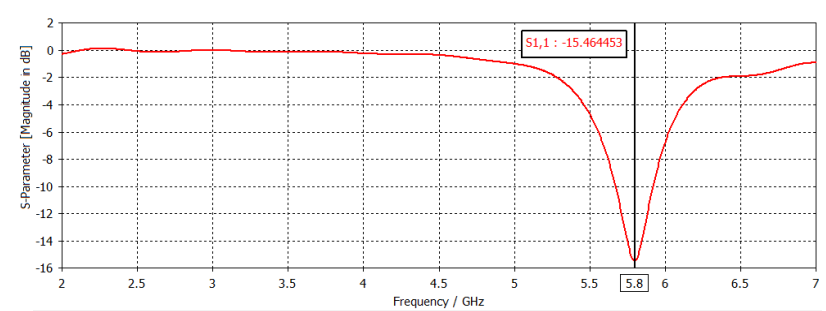

Figure 12. Return loss for Taconic RF 35P.

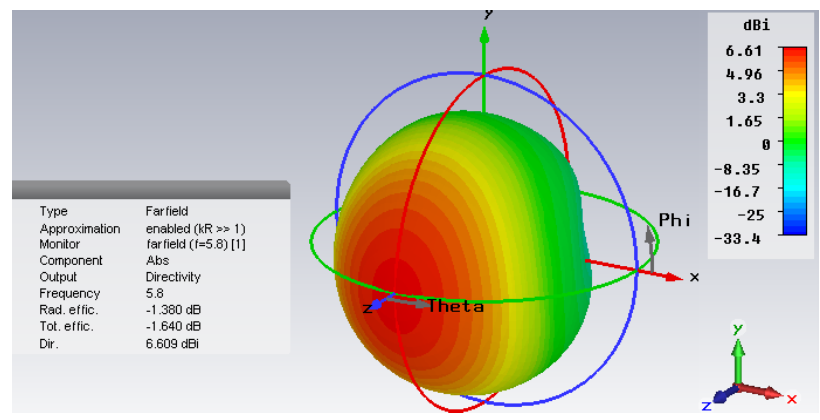

Figure 13. Far field region for Taconic RF 35P.

Farfield Gain Abs (Phi=90)

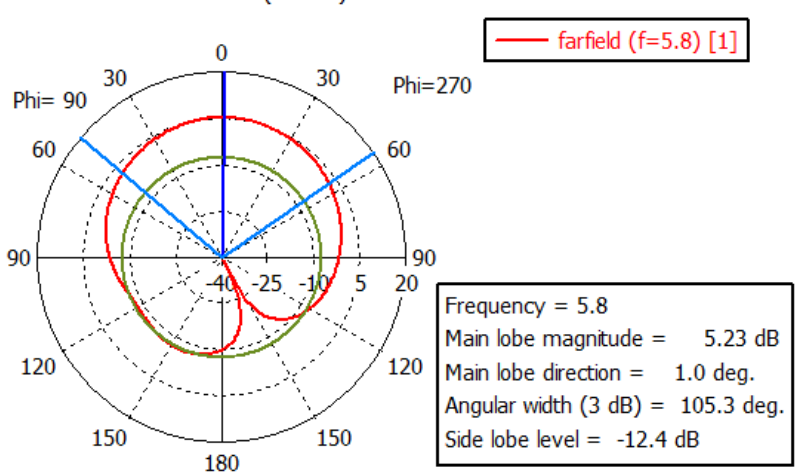

Theta / Degree vs. dB

Figure 14. Far field in polar view for Taconic RF 35P. 


\section{E. Performance of the antenna for Bakelite}

Fig. 15 shows the return loss graph for Bakelite. According to the below figure the value of $\mathrm{S}_{11}$ parameter at $5.8 \mathrm{GHz}$ is $-14.091718 \mathrm{~dB}$.

Fig. 16 shows the far field region. At resonant frequency the radiation efficiency is $-1.382 \mathrm{~dB}$ and total efficiency is $-1.743 \mathrm{~dB}$, which is better for the performance of antenna. Directivity is $6.023 \mathrm{dBi}$. Fig. 17 shows the far field in polar view. According to the figure angular width is $108.7^{\circ}$ and side lobe level is $-11.1 \mathrm{~dB}$ at the resonant frequency.

\section{F. Performance of the antenna for Dupont-951}

Fig. 18 shows the return loss graph for Dupont-951. According to the figure at $5.8 \mathrm{GHz}$ the value of return loss/ $\mathrm{S}_{11}$ parameter is $-16.609992 \mathrm{~dB}$.

Fig. 19 shows the far field region. According to the figure at resonant frequency the radiation efficiency is -1.439

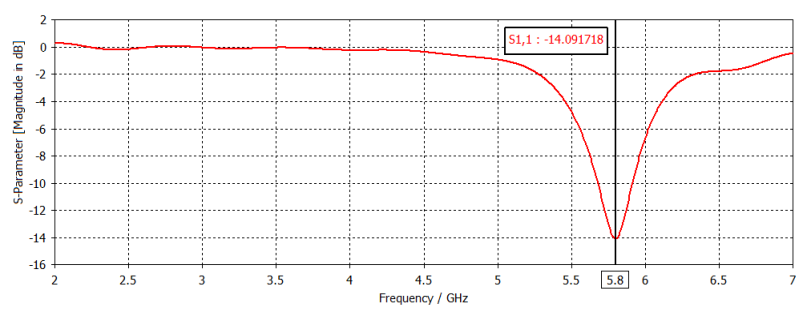

Figure 15. Return loss for Bakelite.

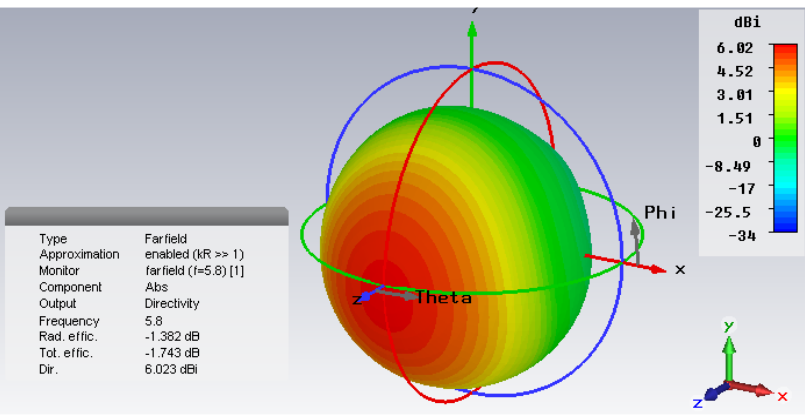

Figure 16. Far field region for Bakelite.

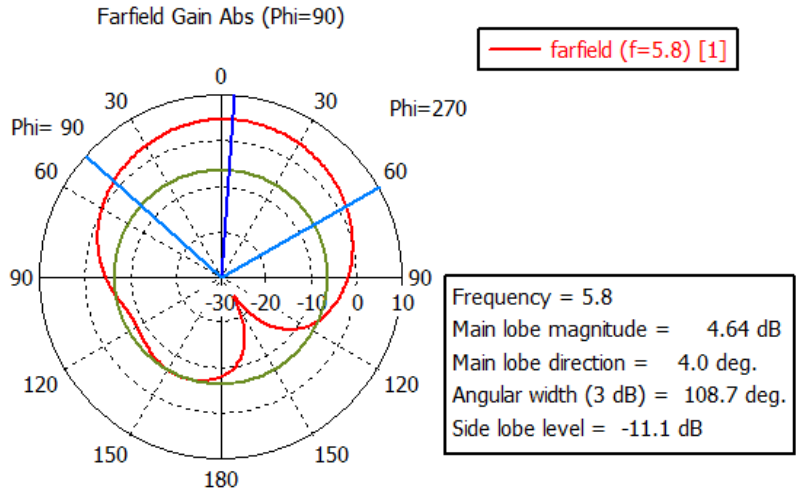

Theta / Degree vs. dB

Figure 17. Far field in polar view for Bakelite.
$\mathrm{dB}$ and total efficiency is $-1.944 \mathrm{~dB}$. From the figure it can be seen that directivity is in $\mathrm{Z}$-axis on the $\mathrm{XY}$ plane. Directivity at $5.8 \mathrm{GHz}$ is $5.573 \mathrm{dBi}$. Fig. 20 shows the far field in polar view. From the figure angular width is $105.8^{\circ}$ and side lobe level is $-9.7 \mathrm{~dB}$ at the resonant frequency.

According to Table III that the highest value of return loss is $-16.609 \mathrm{~dB}$, which is for Dupont-951. If Dupont951 is used as substrate material it will give better performance. Also maximum radiation efficiency and total efficiency has been observed for FR4, which also indicates better performance. For FR4 radiation efficiency is -2.776 $\mathrm{dB}$ and total efficiency is $-3.026 \mathrm{~dB}$. If FR4 is used as substrate material it will also give better performance at $5.8 \mathrm{GHz}$. So either Dupont-951 or FR4 can be used as substrate material in microstrip patch antenna for better performance at $5.8 \mathrm{GHz}$.

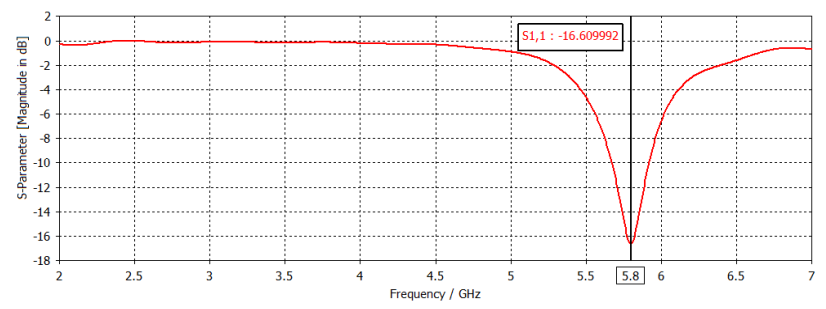

Figure 18. Return loss for Dupont-951.

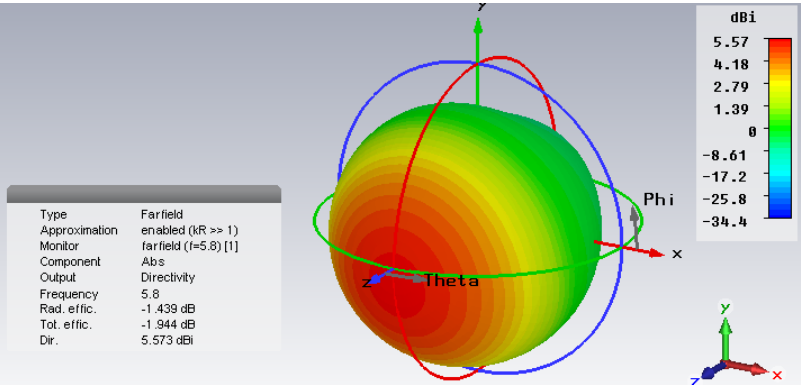

Figure 19. Far field region for Dupont-951.

Farfield Gain Abs (Phi=90)

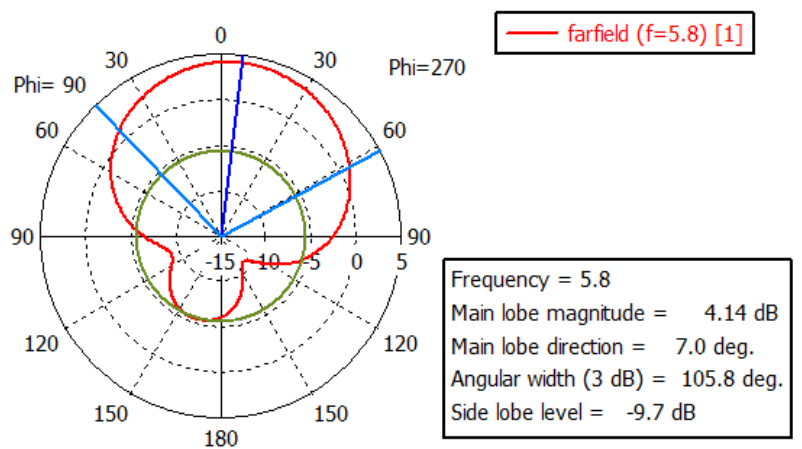

Theta / Degree vs. dB

Figure 20. Far field polar view for Dupont-951. 
TABLE III.

PERFormance Of THE DESIGNED MiCROSTRIP PATCH ANTENNA For 6 DIFFERENT DIELECTRIC MATERIALS AT 5.8 GHZ RESONANT FREQUENCY.

\begin{tabular}{|c|c|c|c|c|c|c|}
\hline \multirow{2}{*}{$\begin{array}{c}\text { Paramet- } \\
\text { ers }\end{array}$} & \multicolumn{6}{|c|}{ Substrate Materials } \\
\hline & FR4 & $\begin{array}{c}R T D u- \\
\text { roid } \\
5880\end{array}$ & $\begin{array}{c}\text { Arlon Di } \\
522\end{array}$ & $\begin{array}{l}\text { Taconic } \\
\text { RF 35P }\end{array}$ & Bakelite & $\begin{array}{c}\text { Dupont- } \\
951\end{array}$ \\
\hline $\begin{array}{c}\text { Dielec. } \\
\text { Constant }\end{array}$ & 4.3 & 2.2 & 2.5 & 3.5 & 4.8 & 7.8 \\
\hline $\begin{array}{c}\text { Res. Freq. } \\
(\mathrm{GHz})\end{array}$ & 5.8 & 5.8 & 5.8 & 5.8 & 5.8 & 5.8 \\
\hline $\begin{array}{c}\text { Return } \\
\text { Loss }(d B)\end{array}$ & -12.421 & -9.693 & -13.821 & -15.464 & -14.091 & -16.609 \\
\hline $\begin{array}{c}\text { Side Lobe } \\
\text { (dB) }\end{array}$ & -10.5 & -14.71 & -15.3 & -12.4 & -11.1 & -9.7 \\
\hline Gain $(d B)$ & 3.332 & 6.462 & 6.065 & 5.228 & 4.641 & 4.134 \\
\hline$V S W R$ & 1.6291 & 1.9743 & 1.51149 & 1.4055 & 1.4920 & 1.3467 \\
\hline $\begin{array}{c}\text { Directivity } \\
\text { (dBi) }\end{array}$ & 6.108 & 7.282 & 7.078 & 6.609 & 6.023 & 5.573 \\
\hline $\begin{array}{l}\text { Radi. Effic. } \\
\text { (dB) }\end{array}$ & -2.776 & -0.8192 & -1.013 & -1.380 & -1.382 & -1.439 \\
\hline $\begin{array}{c}\text { Total Effic. } \\
\text { (dB) }\end{array}$ & -3.026 & -1.487 & -1.553 & -1.640 & -1.743 & -1.944 \\
\hline
\end{tabular}

\section{CONCLUSION}

Today is the era of wireless communications system. WiMAX communication system is widely used around the world. So the use of microstrip patch antenna is increasing day by day. The designed antenna has been miniaturized. The most important factor for the performance analysis of antenna is return loss, radiation efficiency, total efficiency, VSWR. After analyzing the above factors for the 6 mentioned dielectric materials, better performance at $5.8 \mathrm{GHz}$ resonant frequency was observed for both FR4 and Dupont-951. If FR4 or Dupont-951 is used in the substrate layer, designed microstrip patch antenna will provide better performance for WiMAX communication system.

\section{REFERENCES}

[1] Pinki Kumari, Abhishek Vaish, Brainwave based user identification system: A pilot study in robotics environment, Robotics and Autonomous Systems, Available online 11 December 2014.

[2] Semwal, V. B., et al. "Biped model based on human Gait pattern parameters for sagittal plane movement." Control, Automation, Robotics and Embedded Systems (CARE), 2013 International Conference on 2013. http://dx.doi.org/10.1109/care.2013.6733750

[3] Indrasen Singh, Dr. V.S. Tripathi, Micro strip Patch Antenna and its Applications: a Survey, Indrasen Singh et al, Int. J. Comp. Tech. Appl., Vol 2 (5), 1595-1599.

[4] Antenna Theory: Analysis and Design, Constantine A. Balanis, 3rd Edition 2005.

[5] Website. [Online]. Available: https://www.pasternack.com/tcalculator-microstrip-ant.aspx Accessed: 03-01-2016.

[6] Joshua Madhukar Singh, Mayank Mishra, Prafull Sharma, Design \& Optimization of Microstrip Patch Antenna.

[7] Nikita Sharma, Bhawana Jain, Pradeep Singla, Raj Ranjan Prasad, RECTANGULAR PATCH MICRO STRIP ANTENNA: A SURVEY, International Advanced Research Journal in Science, Engineering and Technology, Vol. 1, Issue 3 November 2014

[8] Website. [Online]. Available: http://www.griet.in/ece/notes/210 3 1_A_55022_microstrip-antenna-notes.pdf Accessed: 22-08-2015

[9] Website. [Online]. Available: http://www.ukessays.com/essays/ biology/basic-operation-principle-of-rectangular-microstripantenna-biology-essay.php Accessed: 22-08-2015

[10] G. Sharma, D. Sharma and A. Katariya (2012) An Approach to Design and Optimization of WLAN Patch Antennas for Wi-Fi Applications. IJECCT,2(2),18-23.

\section{AUTHORS}

Md. Moidul Islam, Raja Rashidul Hasan, Md. Mostafizur Rahman, Kazi Saiful Islam, S.M. Al-Amin are with American International University-Bangladesh (AIUB), Dhaka, Bangladesh.

Submitted 17 February 2016. Published as resubmitted by the authors 15 March 2016. 